\title{
HUBUNGAN PENGETAHUAN ANAK TENTANG JENIS JAJANAN DENGAN KARIES GIGI PADA MURID SMP NEGERI 1 PEUKAN BADA KABUPATEN ACEH BESAR
}

\author{
Ratna Wilis*, Wirza \\ Jurusan Keperawatan Gigi Poltekkes Kemenkes Aceh, Indonesia \\ Jl. Soekarno Hatta Desa Lagang Kecamatan Darul Imarah Kabupaten Aceh Besar \\ * Korespondensi penulis: wirza81@gmail.com
}

\begin{abstract}
ABSTRAK
Latar Belakang: Hasil pemeriksaan dan wawancara awal oleh peneliti terhadap 30 orang murid SMPN 1 Peukan Bada Kabupaten Aceh Besar peroleh rata-rata DMF-T/def-t mencapai 2,02 (kategori rendah), yang berpengetahuan rendah tentang jenis jajanan berjumlah 12 murid (40\%) dan yang berpengetahuan tinggi tentang jenis jajanan berjumlah 18 murid (60\%). Penelitian ini bertujuan untuk mengetahui hubungan pengetahuan anak tentang jenis jajanan dengan karies gigi pada murid SMPN 1 Peukan Bada Kabupaten Aceh Besar.

Metode: Penelitian ini bersifat analitik, Populasi dalam penelitian ini adalah seluruh murid di SMPN 1 Peukan Bada sebanyak 372 murid. Pengambilan sampel dengan menggunakan proporsional sampling yaitu berjumlah 79 murid.

Hasil: murid yang memiliki pengetahuan tinggi dengan kriteria karies sedang berjumlah 17 orang (29,8\%). Hasil uji statistik didapat nilai $\mathrm{p}$ sebesar 0,196 sedangkan $\alpha=0,05$ dan $\mathrm{df}=4$. Oleh karena $\mathrm{p}>\alpha$, sehingga Ha ditolak, yaitu tidak ada hubungan pengetahuan anak tentang jenis jajanan dengan karies gigi pada Murid SMPN 1 Peukan Bada Kabupaten Aceh Besar Tahun 2018.

Kesimpulan: Tidak ada hubungan pengetahuan anak tentang jenis jajanan dengan karies gigi pada Murid SMPN 1 Peukan Bada Kabupaten Aceh Besar..
\end{abstract}

Kata Kunci: pengetahuan; jenis makanan; karies gigi.

\section{THE RELETIONSHIP OF CHILDRENS KNOWLEDGE ABOUT FOOD TYPES WITH DENTAL CARE IN SMP NEGERI 1 PEUKAN BADA KABUPATEN}

\section{ABSTRACT}

Background: Test results and initial interviews by the investigators of the 30 students of SMPN 1Peukan Bada, Aceh Besar gained an average of DMF-T / def-t reaches 2.02 (low category), the lower knowledgeable about the types of snacks were 12 pupils (40\%) and the high knowledgeable about the types of snacks were 18 pupils (60\%). This study aims to determine the relationship of knowledge about the types of snacks children with dental caries in the SMPN 1 students Peukan Bada, Aceh Besar.

Methods: This study was analytical, The population in this study were all students at SMPN 1 Peukan Bada many as 372 students. Sampling by using proportional sampling is numbered 79 students.

Results: The results showed that students who have a high knowledge with caries criteria were numbered 17 people (29.8\%). Statistical test results obtained $p$ value of 0.196 , while $\alpha=0.05$ and $d f=4$. Therefore $p>\alpha$, so that Ha rejected, there is no relationship of knowledge about the types of snacks children with dental caries in students SMPN 1Peukan Bada, Aceh Besar.

Conclusion: No relationship of knowledge about the types of snacks children with dental caries in the SMPN 1 Peukan Bada, Aceh Besar district..

Keyword: knowledge; food types; dental caries. 


\section{PENDAHULUAN}

Pembangunan kesehatan bertujuan untuk meningkatkan kesadaran, kemauan, dan kemampuan hidup sehat bagi setiap orang, agar terwujud derajat kesehatan masyarakat yang optimal meliputi kesehatan fisik, mental dan sosial. Undang-Undang Kesehatan No.36 Tahun 2009 pasal 47 yang menyatakan bahwa untuk mewujudkan derajat kesehatan yang setinggitingginya bagi masyarakat, diselenggarakan upaya kesehatan yang terpadu dan menyeluruh dalam bentuk upaya kesehatan perorangan dan upaya kesehatan masyarakat. Upaya kesehatan diselenggarakan dalam bentuk kegiatan dengan pendekatan promotif, preventif, dan rehabilitatif yang dilaksanakan secara terpadu, menyeluruh, dan berkesinambungan. ${ }^{1}$

Pendidikan kesehatan gigi adalah usaha terencana dan terarah untuk mengubah prilaku mereka dari yang kurang menguntungkan menjadi menguntungkan terhadap kesehatan gigi dan mulutnya. Melalui kegiatan ini diharapkan mereka menjadi tahu, mau, dan mampu memecahkan berbagai persoalan yang dihadapi, baik secara mandiri maupun bersama, guna terus meningkatkan kesehatan gigi dan mulut sendiri dan keluarganya. ${ }^{2}$ Kelompok masyarakat diberi motivasi untuk memperbaiki cara pemeliharaan kesehatan gigi melalui pendidikan kesehatan gigi. Usaha pendidikan kesehatan gigi untuk memotivasi pemeliharaan kesehatan gigi belum terwujud dengan baik. Terbukti hasil survai kesehatan gigi Depkes RI tahun 1990, angka penyakit jaringan penyangga gigi dan gigi berlubang masih cukup tinggi. ${ }^{3}$

Besar kecilnya pengaruh faktor resiko terhadap timbulnya karies pada anak sekolah dipengaruhi oleh pengetahuan, kesadaran dan kebiasaan dalam merawat kesehatan gigi, kebiasaan yang perlu dimiliki anak antara lain cara membersihkan gigi serta jajanan/makanan manis. ${ }^{4}$ Bagi masyarakat Indonesia, kebiasaan jajan cenderung menjadi bagian budaya dari satu keluarga. Tidak sedikit masalah timbul akibat jajanan yang tidak memperhatikan mutu gizi, kebersihan dan keamanannya. Makanan yang tidak aman dan tidak bergizi menimbulkan penyakit, ${ }^{5}$

Anak lebih rentan mengalami karies gigi, karena pada umumnya keadaan kebersihan mulut pada anak lebih buruk dan anak lebih banyak makan makanan serta minuman yang menyebabkan karies dibandingkan dengan orang dewasa. Anak-anak umumnya senang makanmakanan yang mengandung gula. Apabila anak terlalu banyak makan gula dan jarang membersihkannya, maka giginya banyak yang mengalami karies. Bagitu dengan ibu hamil yang tidak memiliki pengetahuan atas pemeliharaan kesehatan gigi mulut maka tingkat penjagaan kebersihan mulutnya juga rendah ${ }^{6}$

Penyebab masih tingginya prevalensi karies terjadi karena kebiasaan makan makanan manis dan lengket yang dilakukan dalam kegiatan sehari-hari pada anak usia sekolah. Mereka makan saat sedang bermain, menonton televisi, belajar dan sebelum tidur. Kondisi ini memperbesar kemungkinan tertinggalnya sisa makanan didalam mulut, sehingga mempermudah pertumbuhan mikroorganisme penyebab karies. Diantara kerugian yang paling banyak disorot dari pemakaian gula pasir dalam makanan bergula seperti permen, snack, minuman adalah kerusakan atau pengeroposan gigi, terutama pada anak-anak, karena dapat menyebabkan kerusakan atau karies gigi, maka gula digolongkan sebanyak senyawa kariogenik.?

Berdasarkan Riset Kesehatan Dasar tahun 2018, pengalaman karies gigi masyarakat Indonesia dengan indeks DMF-T/def-t masih tinggi yaitu 7,1. Pengalaman karies pada masyarakat provinsi Aceh dengan rata-rata DMF-T sebesar 4,0 (kategori sedang) dan pengalaman karies menurut karakteristik (WHO) umur 12 tahun dengan rata-rata DMF-T sebesar 1,4 (kategori rendah). Data proporsi rerata nasional perilaku konsumsi kurang sayur dan buah 9,4\%. Perilaku konsumsi makanan beresiko pada penduduk umur $\geq 10$ tahun paling banyak konsumsi bumbu penyedap (77,6\%), diikuti makanan manis $(40,1 \%)$ dan minuman manis $(61,7 \%)$, dan makanan berlemak $(41,7 \%){ }^{8}$

Berdasarkan hasil penelitian yang telah dilakukan oleh Agus pada anak kelas II $-\mathrm{V}$ sejumlah 47 anak di SDN 1 Gogodalem kecamatan bringin kabupaten semarang tahun 2013, didapatkan hasil bahwa anak yang mengalami karies gigi lebih banyak terjadi pada anak yang mengkonsumsi makanan kariogenik dalam kategori tinggi sejumlah 95,0\% dibandingkan anak yang mengkonsumsi makanan kariogenik kategori rendah sejumlah $28,6 \%(14,9 \%) .{ }^{9}$

Berdasarkan hasil pemeriksaan dan wawancara oleh peneliti terhadap 30 orang murid SMPN 1 Peukan Bada Kabupaten Aceh Besar diperoleh rata-rata DMF-T/def-t mencapai 2,02 (kategori rendah), yang berpengetahuan rendah tentang jenis jajanan berjumlah 12 murid (40\%) dan yang berpengetahuan tinggi tentang jenis jajanan berjumlah 18 murid $(60 \%)$.

Berdasarkan data tersebut maka penulis tertarik untuk melakukan penelitian tentang hubungan pengetahuan anak tentang jenis 
jajanan dengan karies gigi pada murid SMPN 1 Peukan Bada Kabupaten Aceh Besar.

\section{METODE}

Penelitian ini bersifat analitik, dengan pendekatan cross sectional untuk mengetahui hubungan pengetahuan anak tentang jenis jajanan dengan karies gigi pada murid SMPN 1Peukan Bada Kabupaten Aceh Besar. Populasi dalam penelitian ini adalah seluruh murid di SMPN 1 Peukan Bada sebanyak 372 murid. Pengambilan sampel dengan menggunakan proporsional sampling yaitu berjumlah 79 murid.Variabel independen (pengaruh) yaitu: pengetahuan tentang jenis jajanandan variabel dependen (terpengaruh) yaitu: karies gigi

Intrumen yang digunakan dalam penelitian ini adalah kuesioner, kartu status pasien dan diagnosa set. Analisis data pada penelitian ini menggunakan uji statistik dengan uji chi square $p<0,05$

\section{HASIL DAN PEMBAHASAN}

Penelitian ini dilaksanakan di SMPN 1 Peukan Bada Kabupaten Aceh Besar dengan jumlah sampel yang dijadikan sebagai responden adalah 79 murid. Berdasarkan pengolahan data diperoleh hasil yang dapat dilihat pada tabel 1 .

Berdasarkan tabel 1 terlihat bahwa dari 79 responden ternyata paling banyak adalah yang berpengetahuan tinggi tentang jenis jajanan berjumlah 57 murid $(72,2 \%)$, serta indeks paling banyak pada kriteria karies sedang sebanyak 23 orang $(29,1 \%)$.

Hubungan antara variabel independen yaitu, Berdasarkan tabel 3 diketahui bahwa murid yang memiliki pengetahuan tinggi dengan kriteria karies sedang berjumlah 17 orang (29,8\%). Berdasarkan uji Chi Square didapat nilai $p$ sebesar 0,196 sedangkan $\alpha=0,05$ dan $\mathrm{df}$ $=4$. Oleh karena $p>\alpha$, sehingga Ha ditolak, yaitu tidak ada hubungan pengetahuan anak tentang jenis jajanan dengan karies gigi pada Murid SMPN 1 Peukan Bada Kabupaten Aceh Besar.

Peneliti berpendapat meskipun anak memiliki pengetahuan tentang jenis jajanan, hal ini tidak mempengaruhi karies gigi anak. Apabila pengetahuan tidak dibarengi dengan sikap dan tindakan dalam melakukan perilaku mengonsumsi berbagai jenis jajanan sehingga dapat menyebabkan karies gigi. Hal ini sesuai dengan teori yang menyatakan bahwa pengetahuan yang cenderung baik, kurang memotivasi untuk bersikap dan melakukan tindakan pemeliharaan kesehatan gigi dan mulut, sehingga status kesehatan gigi dan mulut relatif rendah dengan banyaknya timbul karies gigi. ${ }^{10}$

Pengetahuan mengenai kesehatan gigi juga merupakan faktor penting dalam mempengaruhi terjadinya karies, kurangnya kesadaran, serta perilaku yang mempengaruhi baik buruknya kebersihan gigi dan mulut sangat mempengaruhi tingkat karies gigi. ${ }^{11}$

Pengetahuan anak tentang jenis jajanan tidak berhubungan secara langsung dengan status karies gigi karena pengetahuan tinggi saja belum cukup untuk mempengaruhi status karies gigi anak jika pengetahuan tersebut belum diterapkan dalam perilaku sehari-hari, artinya karies gigi anak tidak hanya dipengaruhi oleh pengetahuan tentang jenis jajanan, terdapat faktor lain yang dapat mempengaruhi kejadian karies gigi seperti frekuensi makan, tingkat konsumsi makanan kariogenik, makanan yang mudah lengket dan menempel di gigi seperti permen dan coklat yang memudahkan terjadinya karies. Sesuai dengan teori yang menyatakan pengetahuan kesehatan gigi seseorang tidak berhubungan secara langsung dengan status karies giginya. ${ }^{12}$

Tabel 1. Distribusi frekuensi responden berdasarkan hubungan pengetahuan anak tentang jenis jajanan dengan karies gigi pada Murid SMPN 1 Peukan Bada Kabupaten Aceh Besar

\begin{tabular}{|c|c|c|c|c|c|c|c|c|c|c|c|c|c|}
\hline \multirow[b]{2}{*}{ Pengetahuan } & \multicolumn{10}{|c|}{ Status Karies Gigi } & \multirow{2}{*}{ Jumlah } & \multirow[b]{2}{*}{$\%$} & \multirow{2}{*}{$\begin{array}{c}\text { Uji } \\
\text { Statistik }\end{array}$} \\
\hline & $\begin{array}{l}\text { Sangat } \\
\text { rendah }\end{array}$ & $\%$ & Rendah & $\%$ & Sedang & $\%$ & Tinggi & $\%$ & $\begin{array}{c}\text { Sangat } \\
\text { Tinggi }\end{array}$ & $\%$ & & & \\
\hline Rendah & 3 & 13,6 & 0 & 0 & 6 & 27,3 & 7 & 31,8 & 6 & 27,3 & 22 & 100 & \multirow{3}{*}{$\begin{array}{c}\mathrm{df}=4 \\
\mathrm{p}=0,196 \\
\alpha=0,05\end{array}$} \\
\hline Tinggi & 11 & 19,3 & 9 & 15,8 & 17 & 29,8 & 10 & 17,5 & 10 & 17,5 & 57 & 100 & \\
\hline Total & 14 & 17,7 & 9 & 11,4 & 23 & 29,1 & 17 & 21,5 & 16 & 20,3 & 79 & 100 & \\
\hline
\end{tabular}


Seseorang yang berpengetahuan tinggi saja belum cukup untuk mempengaruhi status karies giginya menjadi rendah apabila pengetahuan tersebut belum diterapkan dalam perilaku sehari-hari. Diperlukan upaya-upaya untuk memotivasi murid agar pengetahuan kesehatan gigi yang dimilikinya dapat diwujudkan dalam perilaku kesehatan giginya sehari-hari. Pada penelitian yang dilakukan di kota Jambi, pengetahuan ibu juga turut berperan dalam pemeliharaan gigi anak dan status karies gigi anak ${ }^{13}$

Banyak sekali faktor yang menyebabkan karies, diantaranya gigi dan air ludah, adanya bakteri penyebab karies, makanan yang kita konsumsi, makanan yang mudah lengket dan menempel di gigi seperti permen dan coklat, memudahkan terjadinya karies. Sementara itu faktor lain yang turut andil adalah tingkat kebersihan gigi dan mulut, frekuensi makan, usia, dan jenis kelamin, penyakit yang sedang diderita seperti kencing manis dan TB, serta sikap/prilaku terhadap pemeliharaan kesehatan. ${ }^{13}$

Hasil penelitian ini sejalan dengan hasil penelitan terdahulu dengan hasil penelitian didapatkan kesimpulan tidak ada hubungan yang bermakna antara frekuensi konsumsi makanan kariogenik dengan karies gigi. ${ }^{14}$ hasil penelitian lain juga menunjukkan bahwa di daerah Tondano Barat menunjukkan bahwa, pola konsumsi makanan manis yang tinggi tidak diiringi dengan staus karies. Hasil penelitian menunjukkan status karies yang masuk ke dalam kategori rendah. ${ }^{15}$

Berbeda halnya dengan penelitian yang dilakukan Hana Yuan Kartikasari yang menunjukan bahwa ada hubungan konsumsi makanan kariogenik dengan kejadian karies gigi $(p=0,009)$ pada anak kelas III dan IV SDN kadipaten I dan II kabupaten Bojonegoro. Hasil ini menunjukan bahwa semakin anak melakukan tindakan konsumsi makanan kariogenik, maka akan semakin tinggi indeks karies giginya. Jenis makanan yang sering dikonsumsi dapat mempengaruhi keparahan karies gigi. ${ }^{16}$

\section{KESIMPULAN}

Berdasarkan hasil penelitian dan pembahasan, dapat disimpulkan bahwa pengetahuan murid tentang jenis jajanan berada pada kategori tinggi berjumlah 57 murid $(72,2 \%)$. Karies gigi murid paling banyak pada kriteria sedang sebanyak 23 orang $(29,1 \%)$. Tidak ada hubungan pengetahuan anak tentang jenis jajanan dengan karies gigi pada Murid SMPN 1 Peukan Bada Kabupaten Aceh Besar dengan nilai $p$ sebesar 0,196 sedangkan $\alpha=0,05$ dan $\mathrm{df}=4$.
Berdasarkan hasil kesimpulan, maka kepada seluruh murid SMPN 1 Peukan Bada Kabupaten Aceh Besar agar lebih meningkatkan pengetahuan tentang jenis jajanan yang berpengaruh terhadap kesehatan gigi dan mulut khususnya karies gigi.Perlu dilakukan penelitian lanjutan dengan meneliti variabel - variabel lain sehingga dapat diketahui faktor - faktor yang berhubungan dengan pengetahuan anak tentang jenis jajanan dengan karies gigi.

\section{DAFTAR PUSTAKA}

1. Depkes RI. 2009. Undang-Undang R.I No 36 Tahun 2009 Tentang Kesehatan Departemen Kesehatan R.I. Jakarta : Departemen Kesehatan RI. 2009

2. Astoeti TE. Total Quality Management dalam pendidikan kesehatan gigi di sekolah. Jakarta: PT Raja Grafindo Persada. 2006:20-30.

3. Nugraheni H, Sadimin S, Sukini S. Determinan Perilaku Pencegahan Karies Gigi Siswa Sekolah Dasar di Kota Semarang. Jurnal Kesehatan Gigi. 2019 Jun 4;6(1):26-34.

4. Suyuti M. Pengaruh makanan serba manis dan lengket terhadap terjadinya karies gigi pada anak usia 9-10 tahun di SD Negeri Monginsidi II Makassar. Media Kesehatan Gigi. 2010;2:14.

5. Noviani K, Afifah E, Astiti D. Kebiasaan jajan dan pola makan serta hubungannya dengan status gizi anak usia sekolah di SD Sonosewu Bantul Yogyakarta. Jurnal Gizi dan Dietetik Indonesia (Indonesian Journal of Nutrition and Dietetics). 2016 Aug 30;4(2):97-104.

6. Veriza E, Riyadi S. Hubungan Pengetahuan Dan Sikap dengan Motivasi Ibu Hamil Tentang Pemeliharaan Kesehatan Gigi Dan Mulut di Puskesmas Putri Ayu Kota Jambi. Jurnal Bahana Kesehatan Masyarakat (Bahana of Journal Public Health). 2018 May 30;2(1):1-5.

7. Ramadhan AG. Serba serbi kesehatan gigi dan mulut. Jakarta: Bukune. 2010;186.

8. Kemenkes RI. Laporan Nasional Riskesdas 2018. Jakarta: Badan Penelitian dan Pengembangan Kesehatan. 2018.

9. Rosidi A, Haryani S, Adimayanti E. Hubungan Antara Konsumsi Makanan Kariogenik dengan Kejadian Karies Gigi Pada Anak SDN 1 Gogodalem Kec. Bringin Kab. Semarang. InProsiding Seminar Nasional \& Internasional 2014.

10. Rahmandini AK, Sulastri S, Hidayati S. Gambaran Pengetahuan dan Sikap Ibu Tentang Makanan Kariogenik dengan Jumlah Karies Gigi pada Siswa Kelas Iv Sd Negeri Demakijo 1. Journal of Oral Health Care. 2017 Apr 2;5(1).

11. Ariyanto A. Faktor-Faktor Yang Berhubungan Dengan Perilaku Pemeliharaan Kebersihan Gigi Dan Mulut di Kelurahan Wonoharjo Kabupaten Tanggamus. Jurnal Analis Kesehatan. 2019 Jan 25;7(2):744-8. 
12. Nurianti I, Bako AD. Hubungan Perilaku Tentang Kesehatan Gigi Dan Mulut Dengan Kejadian Karies Gigi Anak di SD Cinta Rakyat 4 Kelas IV dan V. Jurnal Penelitian Kesmasy. 2018 Oct 18;1(1):9-13.

13. Sukarsih S, Silfia A, Febrianti S. Hubungan Pengetahuan Ibu Tentang Pemeliharaan Kesehatan Gigi Dengan Status Karies Pada Anak TK Al-Hikmah Kota Jambi Tahun 2018. Jurnal Bahana Kesehatan Masyarakat (Bahana of Journal Public Health). 2018 Dec 31;2(2):131-8.

14. Kusumawardani E. Buruknya kesehatan gigi dan mulut. Hanggar korektor, Yogyakarta. 2011.
15. Mamengko W, Kawengian SE, Siagian KV. Gambaran konsumsi jajanan dan status karies pada anak usia 3-5 tahun di Kelurahan Rinegetan Kecamatan Tondano Barat. e-GiGi. 2016;4(1).

16. Kartikasari HY, Nuryanto N. Hubungan konsumsi makanan kariogenik dengan kejadian karies gigi dan status gizi pada anak kelas III dan IV SDN Kadipaten I dan II Kabupaten Bojonegoro (Doctoral dissertation, Diponegoro University). 